\title{
Surface sublimation of zinc blende CdTe
}

Y. S. Wu, C. R. Becker, A. Waag, K. von Schierstedt, R. N. Bicknell-Tassius, and $\mathrm{G}$. Landwehr

Physikalisches Institut der Universität Würzburg D-8700 Würzburg, Germany

(Received 18 September 1992; accepted for publication 4 January 1993)

The surface sublimation of $\mathrm{Cd}$ and $\mathrm{Te}$ atoms from the zinc blende (111) $A \mathrm{CdTe}$ surface has been investigated in detail by reflection high energy electron diffraction and $\mathrm{x}$-ray photoelectron spectroscopy. These experiments verify that $\mathrm{Te}$ is much easier to evaporate than $\mathrm{Cd}$. The experimental value for the Te activation energy from a Te stabilized (111) $A$ CdTe surface is $1.41 \pm 0.10 \mathrm{eV}$, which is apparently inconsistent with recent theoretical results.

Recently, considerable attention has been paid to the study of surface sublimation of CdTe and $\mathrm{HgTe}$ in theoretical ${ }^{1-3}$ as well as experimental investigations using molecular beam epitaxially (MBE) grown samples. ${ }^{4-6}$

Many attempts have been made to determine the activation energy for surface sublimation processes in various experiments on $\mathrm{CdTe},{ }^{7,8} \mathrm{GaAs},{ }^{9,10} \mathrm{ZnSe},{ }^{11}$ or compounds containing these materials, but the reported values differ substantially. This may be because different experimental conditions were used. For example, if high energy electrons are used to observe a surface structure in order to measure the atomic activation energy, one has to consider how these electrons affect the observed surface. In addition, experiments which involve the evaporation of many layers measure quantities which have more to do with bulk cohesive energies than atomic activation energies. The surface condition, such as $\mathrm{Cd}$ and $\mathrm{Te}$ coverage and surface roughness, would also affect the $\mathrm{Cd}$ and $\mathrm{Te}$ lifetimes on a $\mathrm{CdTe}$ surface.

Knowledge concerning the surface structure and which element is easier to remove from the surface is important for crystal growth and other related techniques. The sublimation rate of $\mathrm{Cd}$ is considered by some workers to be higher than that of Te because the bond strength between $\mathrm{Cd}$ atoms is much smaller than that between $\mathrm{Te}$ atoms (2.7 and $54.9 \mathrm{kcal} / \mathrm{mol},{ }^{12}$ respectively), as is the case for the heat of sublimation of atomic $\mathrm{Cd}$ and diatomic Te ( 26.7 and $39.2 \mathrm{kcal} / \mathrm{mol}$, respectively). ${ }^{12}$

Krishnamurthy et $a l^{1,2}$ and Berding, Krishnamurthy, and $\mathrm{Sher}^{3}$ recently reported theoretical calculations of sublimation energies from $\mathrm{Si}, \mathrm{GaAs}, \mathrm{CdTe}$, and $\mathrm{HgTe}$ surfaces which are commercially as well as scientifically important. However, no one has experimentally verified their results, which may influence future work. In this investigation, we present experimental results for the activation energies of $\mathrm{Cd}$ and $\mathrm{Te}$, and thus, information concerning the sublimation of $\mathrm{Cd}$ and $\mathrm{Te}$ from $\mathrm{CdTe}$ surfaces.

According to Krishnamurthy et al., ${ }^{1}$ the Cd sublimation energies for Cd terminated surfaces of CdTe substrates are much less than those of Te from Te terminated surfaces. Therefore, $\mathrm{Cd}$ atoms on $\mathrm{Cd}$ terminated surfaces should be much easier to remove than Te on Te terminated surfaces. For example, their corresponding $\mathrm{Cd}$ and $\mathrm{Te}$ sublimation energies from $\mathrm{Cd}$ and $\mathrm{Te}$ terminated (111) $\mathrm{A}$ CdTe surfaces, i.e., the concentrated case, are 0.6 and 4.2
$\mathrm{eV}$, respectively. ${ }^{1}$ The desorption rate $K_{a}$ is related to the activation energy $E_{\alpha}$ according to the Arrhenius equation

$$
K_{a}=A_{a} \exp \left(-E_{\alpha} / k T\right),
$$

where $A_{a}$ is a frequency factor and $k$ is the Boltzmann constant. Values of $A_{a}$ for $\mathrm{Te}$ and $\mathrm{Cd}$ on $\mathrm{CdTe}$ could be estimated to be $10^{13}$ and $10^{37}$, respectively, from observed changes in the high energy electron diffraction (RHEED) patterns from the concentrated limit to the dilute limit in the literature. ${ }^{7}$ If we use even more extreme values, i.e., $10^{40}$ instead of $10^{13}$ for Te and $10^{5}$ instead of $10^{37}$ for $\mathrm{Cd}$, then $K_{\mathrm{Cd}} \approx 10^{4} \times K_{\mathrm{Te}}$ for the (111)A CdTe surface at $230^{\circ} \mathrm{C}$. Therefore, the $\mathrm{Cd}$ atomic layer should be easily evaporated, and consequently, the surface should be terminated with $\mathrm{Te}$ atoms.

In order to determine whether the calculations of Krishnamurthy et al. ${ }^{1,2}$ correctly predict sublimation energies for CdTe, the following experiment was carried out under conditions as near as possible to those used in their calculations. Consequently, we determined the activation energy for $\mathrm{Cd}$ from a $\mathrm{Cd}$ stabilized surface and for $\mathrm{Te}$ from a Te stabilized surface, i.e., for the removal of atoms in the concentrated limit. ${ }^{4}$ We employed (111) $A$ CdTe terminated by either a triply bonded $\mathrm{Cd}$ atom or a singly bonded $\mathrm{Te}$ atom, as well as $\mathrm{Cd}$ and $\mathrm{Te}$ stabilized (100) and (111) $B$ CdTe. (111) $A \mathrm{CdTe}$ is emphasized in this letter because the theoretical calculations for $\mathrm{Si}$, GaAs, CdTe, and $\mathrm{HgTe}^{1,2}$ predict that the difference between the sublimation energies for the anion and cation is largest for (111) $A$ CdTe. In addition, RHEED patterns for $\mathrm{Cd}$ and Te terminated surfaces are easily distinguishable.

Experimental details have been described in previous publications. ${ }^{4,5}$ The substrates employed in this work were (111) $A$, (111) $B$, and (100) $\mathrm{Cd}_{0.96} \mathrm{Zn}_{0.04} \mathrm{Te}$ and CdTe. During the following, we kept all ovens at temperatures lower than $100{ }^{\circ} \mathrm{C}$, and the main shutter and every individual oven shutter closed. Thus, no $\mathrm{Cd}, \mathrm{Te}$, or CdTe partial pressures were present. The vacuum in the growth chamber during heat treatment was better than $4 \times 10^{-10}$ Torr. If untreated (111)A $\mathrm{Cd}_{0.96} \mathrm{Zn}_{0.04} \mathrm{Te}$ substrates are kept in the MBE growth chamber at temperatures less than $160^{\circ} \mathrm{C}$, spotty RHEED patterns appeared, which is characteristic of untreated CdTe surfaces. At temperatures as low as $170^{\circ} \mathrm{C}$, the RHEED patterns were still spotty, but clear, integral order streaks were present. This is in con- 
trast to (100) CdTe, where heat treating (100) and (111) $B$ CdTe substrates in vacuum normally results in spotty RHEED patterns initially, and then, in modulated integral order and sometimes half-order reconstruction streaks when the substrate temperature is slowly increased up to $250^{\circ} \mathrm{C}$. Only smooth streaks are visible if the substrate is held at $180^{\circ} \mathrm{C}$ or higher for about $15 \mathrm{~min}$. Here, $(1 \times 1)$ reconstruction persists for several tens of seconds, and then $(2 \times 2)$ reconstruction appears. This $(2 \times 2)$ reconstruction becomes stronger for several minutes before reaching saturation. The original $(1 \times 1)$ reconstruction can never be recovered by heating at any temperature without an additional Te flux. $(1 \times 1)$ reconstruction indicates a Te stabilized surface and $(2 \times 2)$ reconstruction a $\mathrm{Cd}$ stabilized surface for the (111) $A \mathrm{CdTe}$ surface, as discussed below. As is well known, CdTe and $\mathrm{Cd}_{0.96} \mathrm{Zn}_{0.04} \mathrm{Te}$ surfaces which have been polished with a solution of $\mathrm{Br}$ in methanol and/or etched in dilute $\mathrm{HCl}$ always contain much more Te than Cd. ${ }^{13,14}$ Thus, Te is preferentially evaporated by this heat treatment. X-ray photoelectron spectroscopy (XPS) measurements of this surface also indicated that the untreated surface was Te rich, i.e., contained more than one atomic layer of $\mathrm{Te}$, but that after heat treatment at about $180^{\circ} \mathrm{C}$, the surface was $\mathrm{Cd}$ terminated. This was accomplished by means of our calibrated atomic sensitivity factors. ${ }^{4}$ We have also heat treated a MBE grown CdTe film on a (111)A $\mathrm{Cd}_{0.96} \mathrm{Zn}_{0.04}$ Te substrate and observed $(2 \times 2)$ reconstruction.

The RHEED pattern during the growth of (111)A $\mathrm{CdTe}$ at $330^{\circ} \mathrm{C}$ displays a very distinct $(2 \times 2)$ reconstruction. The strength of this reconstruction could be reduced by lowering the substrate temperature and it would eventually become $(1 \times 1)$ during growth when the substrate temperature reached approximately $100^{\circ} \mathrm{C}$. The CdTe flux was between 3 and $4 \times 10^{-7}$ Torr. This result indicates that the Te sticking coefficient is much larger than that of $\mathrm{Cd}$ since $(1 \times 1)$ reconstruction is indicative of a $\mathrm{Te}$ terminated surface. At higher temperatures, Te is easily evaporated and the Cd sticking coefficient becomes very small, ${ }^{5}$ which considerably reduces the $\mathrm{CdTe}$ growth rate, as reported by Sivananthan et al. ${ }^{6}$

RHEED observations clearly show that during CdTe growth at $330^{\circ} \mathrm{C}$ and after cooling the film from 330 to $200^{\circ} \mathrm{C}$, the $(2 \times 2)$ reconstruction patterns were almost identical to that of an epilayer in a $\mathrm{Cd}$ environment at $100{ }^{\circ} \mathrm{C}$. If the film is kept in a $\mathrm{Cd}$ environment at room temperature, additional spots superimposed on the streaks appear. This indicates that a pure Cd film is being deposited, which was confirmed by XPS measurements. A Cd flux of $5 \times 10^{-7}$ Torr was employed.

The above smooth $(2 \times 2)$ reconstruction cannot be destroyed by heating at temperatures ranging from room temperature to $300^{\circ} \mathrm{C}$. If the film is held at temperatures higher than $300^{\circ} \mathrm{C}$, half-order reconstruction in the [0 $\left.\overline{1} 1\right]$ azimuth is still present even though the RHEED patterns are modulated. XPS measurements indicated that the surface was terminated by $\mathrm{Cd}$ atoms. In this experiment, we turned off all heating elements with the exception of the substrate heater in order to eliminate as far as possible any partial pressures due to $\mathrm{Cd}$ or Te. These experimental results demonstrate that $\mathrm{Cd}$ remains on the (111)A $\mathrm{CdTe}$ surface when CdTe is sublimed from an (111) $A$ face.

The RHEED pattern of an epilayer in a Te environment at $110^{\circ} \mathrm{C}$ displays a $(1 \times 1)$ reconstruction. At higher temperatures, $230^{\circ} \mathrm{C}$, for example, this $(1 \times 1)$ reconstruction was very easily destroyed if the Te flux is less than $3 \times 10^{-7}$ Torr. The surface structure changes from a $(1 \times 1)$ to a $(2 \times 2)$ reconstruction and cannot be recovered if a Te flux is not present. This means that a Te stabilized surface requires a Te partial pressure. However, if a $(1 \times 1)$ Te terminated surface is placed in a Cd environment, the RHEED patterns immediately change to a $(2 \times 2)$ and never to a $(1 \times 1)$ reconstruction. We have also kept a substrate with a $(1 \times 1)$ surface reconstruction in the growth chamber for $4 \mathrm{~h}$ at room temperature and found no change in the RHEED patterns. Thus, there is no residual $\mathrm{Cd}$ partial pressure in the growth chamber which could change the Te stabilized surface for the conditions mentioned above.

We could not measure the Cd activation energy from the (111) A CdTe face with our method because the $(2 \times 2)$ Cd stabilized surface structure could not be changed during heating. The determination of the Te activation energy from the (111)A surface is described below.

First, we very carefully heat treated the (111) $\mathrm{A}$ $\mathrm{Cd}_{0.96} \mathrm{Zn}_{0.04} \mathrm{Te}$ substrates at $180^{\circ} \mathrm{C}$ which displayed very distinct RHEED patterns. Then, the substrate temperature was raised to $340^{\circ} \mathrm{C}$ in about $10 \mathrm{~min}$ and $\mathrm{CdTe}$ was grown for $1 \mathrm{~h}$ at $330^{\circ} \mathrm{C}$. If either additional dots appear on the original streaks, off angle streaks appear, facets are present ${ }^{6}$ or the (111) $A$ surface becomes wavy as the epilayer thickness is increased, then further growth will not result in an improvement in the structural quality. Because the Te lifetime on the (111) $A$ surface is influenced by the surface structure, ${ }^{4,5}$ a high quality surface as judged by the RHEED patterns is an essential prerequisite for this experiment. After growing a $1-\mu \mathrm{m}$-thick CdTe film, we cooled the substrate to the desired experimental temperature between 150 and $210^{\circ} \mathrm{C}$. Then, the Te oven was opened for several tens of seconds until smooth $(1 \times 1)$ streaks were obtained. Excess $\mathrm{Te}$ atoms on the Te terminated surface was avoided, which would have made the RHEED pattern darker and then produced additional lines. The Te lifetime on the Te stabilized surface was considered to be the persistence time of the $(1 \times 1)$ RHEED pattern after closing the Te shutter and the main shutter. The disappearance of the $(1 \times 1)$ reconstruction was determined by the appearance of a clear half-order reconstruction in the [0 $\overline{1} 1]$ azimuth. The Te converge on the (111) $A$ face was about $80 \%$ as was determined by XPS measurements, when a clear half-order reconstruction appeared. The persistence time measurements were repeatable with an error of about $10 \%$. The experimental dependence of the Te desorption time on the inverse of the substrate temperature is shown in Fig. 1. Using the Arrhenius formula, Eq. (1), we determined the Te activation energy for the Te stabilized (111)A CdTe surface to be $1.41 \pm 0.10 \mathrm{eV}$. 


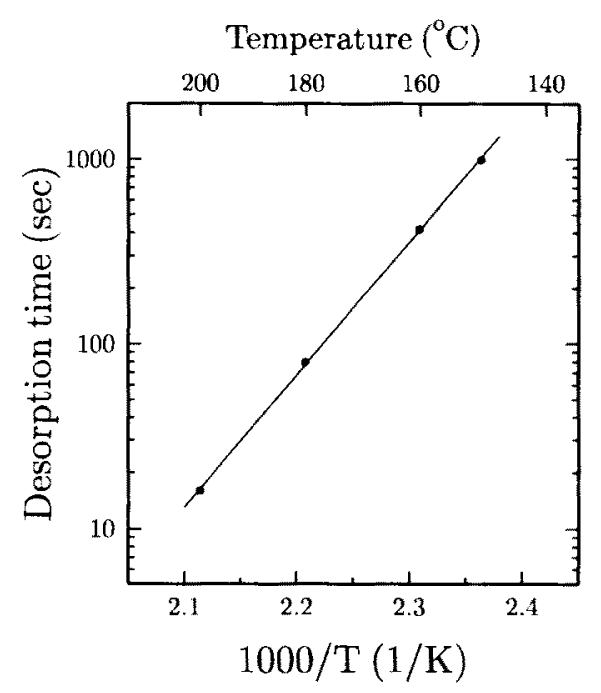

FIG. 1. Measured values of the Te surface lifetime on (111) A CdTe. From these measurements, the activation energy for Te was determined to be $1.41 \pm 0.10 \mathrm{eV}$.

In conclusion, we have experimentally shown that $\mathrm{Te}$ atoms are removed much easier from the (111) $\mathrm{A} \mathrm{CdTe}$ surface than is $\mathrm{Cd}$. The Te activation energy is $1.41 \pm 0.10$ $\mathrm{eV}$, which is much less than the calculated value for sublimation energy. ${ }^{1,2}$ This discrepancy between experiment and theory is probably due to the influence of surface reconstruction which was not included in the theoretical calculations. These results indicate that surface reconstruction could potentially have considerable influence on the surface properties and should be included in surface sublimation calculations.
We gratefully acknowledge support from the Bundesministerium für Forschung und Technologie, Contract No. TK 0369 and the Deutsche Forschungsgemeinschaft. Helpful discussions with W. Schmitt, E. Bangert, L. $\mathrm{He}$, and $\mathrm{S}$. Yuan, as well as photography by $\mathrm{H}$. Koubek and R. Kagerbauer are also acknowledged.

${ }^{\text {'}}$ S. Krishnamurthy, M. A. Berding, A. Sher, and A.-B. Chen, Phys. Rev. Lett. 64, 2531 (1990)

${ }^{2}$ S. Krishnamurthy, M. A. Berding, A. Sher, and A.-B. Chen, J. Appl. Phys. 68, 4020 (1990).

${ }^{3}$ M. A. Berding, S. Krishnamurthy, and A. Sher, J. Vac. Sci. Technol. B 9, 1858 (1991).

${ }^{4}$ Y. S. Wu, C. R. Becker, A. Waag, M. M. Kraus, R. N. BicknellTassius, and G. Landwehr, Phys. Rev. B 44, 8904 (1991).

${ }^{5}$ Y. S. Wu, C. R. Becker, A. Waag, R. N. Bicknell-Tassius, and G. Landwehr, J. Appl. Phys. 69, 268 (1991).

${ }^{6}$ S. Sivananthan, X. Chu, J. Reno, and J. P. Faurie, J. Appl. Phys. 60, 1359 (1986).

${ }^{7}$ J. D. Benson and C. J. Summers, J. Appl. Phys. 66, 5367 (1989); J. D. Benson and C. J. Summers, J. Cryst. Growth 86, 354 (1988); J. D. Benson, B. K. Wagner, A. Torabi, and C. J. Summers, Appl. Phys. Lett. 49, 1034 (1986)

${ }^{8}$ J. J. Dubowski, J. M. Wrobel, and D. F. Williams, Appl. Phys. Lett. 53, $660(1988)$.

${ }^{9}$ J. M. Van Hove and P. I. Cohen, Appl. Phys. Lett. 47, 726 (1985).

${ }^{10} \mathrm{H}$. Yamaguchi and Y. Horikoshi, Phys. Rev. B 44, 5897 (1991).

${ }^{11}$ M. Ohishi, H. Saito, H. Torihara, Y. Fujisaki, and K. Ohmori, Jpn. J. Appl. Phys. 30, 1647 (1991).

${ }^{12}$ Handbook of Chemistry and Physics, 66th ed., edited by R. C. Weast (CRC, Boca Raton, FL, 1985, 1986).

${ }^{13}$ R. D. Feldman, R. L. Opila, and P. M. Bridenbaugh, J. Vac. Sci. Technol. A 3, 1988 (1985); Y.-C. Lu, R. S. Feigelson, and R. K. Route, J. Appl. Phys. 67, 2583 (1990); J. L. Shaw, L. J. Brillson, S. Sivananthan, and J. P. Faurie, ibid. 56, 1266 (1990).

${ }^{14}$ A. Waag, Y. S. Wu, R. N. Bicknell-Tassius, and G. Landwehr, Appl. Phys. Lett. 54, 2662 (1989); Y. S. Wu, C. R. Becker, A. Waag, R. N. Bicknell-Tassius, and G. Landwehr, Appl. Phys. Lett. 60, 1878 (1992). 